\title{
Interface Educação
}

\section{GESTÃO DAS MUDANÇAS EM ORGANIZAÇÕES EDUCACIONAIS}

\author{
Maria Alinele Lucena Soares (1) \\ Ediones Bezerra dos Santos (2) \\ Tereza Ivone Lobo Pinheiro Gurgel (3) \\ Júlia Rosa Santos Sousa (4) \\ Hidemburgo Gonçalves Rocha (5)
}

\begin{abstract}
Resumo
O presente artigo discute a questão das relações no ambiente educacional. Trata-se de um aspecto essencial para o desenvolvimento das empresas e do uso do potencial criativo e laboral das pessoas. As mudanças e o estresse organizacional têm chamado a atenção de um número cada vez maior de empresas preocupadas com o crescimento dos problemas emocionais, relacionais e de saúde, relacionados a estes fenômenos. Os estímulos físicos e psicossociais do estresse podem ser considerados grandes inimigos tanto da saúde, qualidade de vida quanto da produtividade. A gestão das mudanças e do estresse organizacional tem se tornado um assunto estratégico para educadores e gestores educacionais, visto tratar-se de um ambiente de referência para os que dela se utilizam, principalmente os aprendizes. Este artigo é uma revisão bibliográfica sobre os estímulos psicossociais geradores de estresse no contexto das mudanças organizacionais constantes.
\end{abstract}

Palavras-Chave: Estresse, gestão, mudanças organizacionais

\section{Introdução}

Num ambiente que se propõe a educar pessoas, imagina-se um grupo de técnicos treinados, motivados e maduros emocionalmente. Mas nós intuímos que as muitas mudanças por que tem passado as formas de produzir, de aprender, a inserção de novas tecnologias de comunicação, o grande aglomerado de pessoas nas metrópoles, enfim, o desgaste físico e emocional ao qual as pessoas são submetidas nas relações com o ambiente de trabalho é um fator muito significativo na determinação de transtornos de saúde relacionados ao estresse, 
como é o caso das depressões, ansiedade, transtorno de pânico, fobias e doenças psicogênicas (GOLEMAN, 1997-98).

No caso das organizações educacionais, os estímulos estressares são muito variados e em grande quantidade. Pode-se experimentar ansiedade significativa diante de descontentamentos com os colegas, superiores, pais de alunos, diante da sobrecarga de trabalho e da corrida contra o tempo, diante da insatisfação salarial ou da política de recursos humanos, entre outras, e, dependendo da pessoa, até mesmo com tarefas rotineiras de sua própria função dentro do ambiente de trabalho.

Diversas questões emocionais relacionados ao próprio tipo de função no emprego contribuem para que a pessoa mantenha-se excessivamente estressada: a sensação de instabilidade, a sensação de insuficiência profissional, a pressão para comprovação de eficiência, a impressão continuada de estar cometendo erros profissionais, a falta de visão sobre a relevância social do seu trabalho, a percepção de falta de reconhecimento de seus esforços, entre outros. Além disso, as preocupações pessoais não podem ser eliminadas simplesmente ao iniciar um novo dia de trabalho. A pessoa carrega consigo toda a sua história de vida, em todos os momentos, inclusive quando vai para o trabalho. São conflitos, frustrações, desavenças conjugais, preocupação com seus filhos, seus interesses e necessidades pessoais.

Segundo Nahas (2003), existem muitas evidencias de que trabalhadores motivados positivamente produzem mais e são menos acometidos por doenças. Dessa forma, cuidar de si mesmo e de seus colaboradores é mais um desafio para aos que se propõem a uma gestão educacional de sucesso. Um outro desafio poderia ser o fato de que, se observa claramente que as taxas de natalidade tem caído, assim como tem aumentado a expectativa de vida da população. Com isso advém o envelhecimento da força de trabalho e todas as suas consequências. Para que esta força de trabalho envelhecida possa produzir bem, tanto em termos físicos como intelectuais, o estresse precisa ser dosado de forma adequada, uma vez que este é um dos principais fatores de incapacidade funcional precoce quando em excesso.

\section{Considerações sobre o estresse}

O estresse é um conceito emprestado da física. No caso da aplicação em ciências sociais, refere-se a alteração global de nosso organismo para adaptar-se a uma situação nova ou às mudanças de um modo geral (DEITOS, 1997a). 
Trata-se de um mecanismo normal e necessário ao organismo, pois faz com que o ser humano fique mais ativo e sensível diante de situações do dia-a-dia, que exijam respostas ou adaptações, diante do perigo ou de dificuldade. Segundo alguns autores (DEITOS, 1977b; GOLEMAN, 1977), o estresse não é bom nem ruim, pois mesmo situações consideradas positivas e benéficas, como por exemplo, promoções profissionais, casamentos desejados, nascimento de filhos, etc., podem produzir estresse significativo. Assim é considerado um mecanismo essencial para o desenvolvimento de nossa sociedade.

As mudanças fazem parte da vida cotidiana. As pessoas devem estar preparadas para se adaptar a elas o mais rapidamente possível a fim de garantir a sobrevivência. O estresse funciona como um mecanismo de adaptação, necessário para estimular o organismo e melhorar sua atuação diante de circunstâncias novas. Nas dimensões social e cultural, as mudanças cotidianas sempre ocorreram em toda a história da humanidade, elas são à base da evolução da espécie humana.

De acordo com França e Rodrigues (1999, p.18), "não existem evidencias cientificas de que as pessoas na atualidade sofram mais com o estresse do que em outras épocas, onde o esforço, para simplesmente manter-se vivo, era seguramente, maior". Assim, o estresse sofrido na atualidade é diferente do que foi vivenciado em outras épocas devido à tendência secular de aceleração das mudanças impostas, principalmente, pela globalização da economia e pela decadência cultural resultante do mau uso dos meios de comunicação em massa que acabam modificando os valores e criando necessidades de consumo não existentes em épocas passadas. Isso é novo ao ser humano e perigoso à sua saúde, consequentemente a sua vida de relacionamentos. A velocidade sem precedentes com a qual as mudanças e as exigências que elas propiciam, acontecem na vida moderna, representam constante preocupação para as pessoas.

\section{O impacto das mudanças nas pessoas}

As mudanças estão em toda à parte: na tecnologia, na ciência, na educação, na medicina, no ambiente de trabalho, nas estruturas organizacionais, nos valores e costumes sociais, na filosofia e até mesmo na religião. Há continuamente uma enorme solicitação de adaptação às pessoas em geral, tanto para os jovens como para os mais velhos.

As necessidades de mudanças podem ser comparadas a um ciclo vicioso; o momento presente está quase sempre exigindo mudanças, essas mudanças acabam trazendo novos 
problemas. Esses problemas despertam novas soluções, as quais passam a exigir novas mudanças e assim por diante.

Para França e Rodrigues (1999, p.105), "os estressares psicossociais são os acontecimentos relacionados com o tipo de vida que levamos em nossa sociedade". A inserção dos valores sociais, principalmente nos países capitalistas, tem gerado um grande número de estressares psicossociais novos e constantes. Se antes as ameaças à sobrevivência física eram a maior preocupação, hoje temos uma infinidade de ameaças subjetivas construídas na complexidade de nossa estrutura social que constantemente leva a pessoa à alienação.

De acordo com França e Rodrigues (1999, p.106), "a capacidade de gerar riqueza é sinônimo de competência profissional e serve de índice de respeito e consideração que a sociedade emprestará a pessoa". Num modelo de sociedade cujo maior valor é a geração de riqueza econômica, o trabalhador, muitas vezes é considerado, apenas uma peça de uma engrenagem cruel e quando não funciona bem, é substituído.

O estresse ocasionado pelas constantes e brutas mudanças representa um grande perigo à saúde das pessoas e a organização de um trabalho educacional mais eficaz. Saúde aqui entendida como define a Organização Mundial de Saúde, como o mais completo possível estado de bem estar físico, emocional, social, intelectual e espiritual. Goleman (1998), nos informa que as constantes mudanças exigem alterações de papeis sociais de forma rápida e muitas vezes, sem o devido período de transição.

Segundo França e Rodrigues (1999, p.107), " papel é toda função, acompanhada de um conjunto de condutas próprias para aquela função, que a pessoa desempenha em determinado momento de sua vida". As grandes demandas pela qualidade do trabalho educacional, juntamente com a grande competitividade entre essas empresas tem induzido a mudanças e acúmulo de papeis, determinadas por diversos fatores como: as mudanças determinadas pela legislação, pela própria empresa, devidas a novas tecnologias, devidas a mudanças autoImpostas para sobrevivência dos colaboradores no mercado de trabalho.

Para Maslach (1998), é de muita importância que a pessoa desempenhe um papel adequado e coerente com suas condições pessoais e profissionais, pois isso motiva e facilita o bom desempenho. As mudanças determinadas pela equipe de gestores educacionais, podem ser originadas por uma nova chefia ou devido à nova orientação geral da instituição.Normalmente todo tipo de mudança gera muita insegurança. $\mathrm{O}$ aumento do nível de estresse, inevitavelmente acontece diante das mudanças. O que mais se solicita das pessoas é a adaptação aos novos papeis, portanto, é o momento onde o estresse está acontecendo. As 
pessoas possuidoras de dificuldades físicas, emocionais ou sociais, naturalmente sofrerão mais nesse processo. Abrir mão de métodos e papeis usuais para aprender ou aceitar novos sempre exige um esforço emocional significativo.

\section{O estresse gerado pelas novas tecnologias}

A tecnologia está em contínua transformação. Novos sistemas impactam todos os dias as instituições. Nessa situação também as pessoas são emocionalmente solicitadas a se adaptar ao novo. Nesse caso o estresse será variável, de acordo com as disposições Pessoais e de acordo com o tipo dessa nova tecnologia a ser implantada. Geralmente as pessoas que tiveram em suas histórias de vida, pouco contato com as novas tecnologias, são esmagadas pelas tensões decorrentes de ter que se adaptar rapidamente a uma máquina ou software.

Goleman (1995) afirma que, por tendência pessoal sofrerão mais aqueles com instabilidade afetiva, com traços marcantes de ansiedade ou já previamente estressados em excesso com as expectativas negativas em relação às mudanças. Em relação às próprias mudanças, sofrerão mais as pessoas confrontadas com novas tecnologias ideologicamente diferentes das anteriores.

A expectativa negativa em relação às novas tecnologias no trabalho, muitas vezes é decorrente do paradoxo existente entre os dois, pois a tecnologia no trabalho que deveria facilitar a vida do trabalhador muitas vezes apenas substitui o trabalhador. É de conhecimento popular que nas empresas, as máquinas extinguiram muitos postos de trabalho, ampliando as responsabilidades e monotonizando os postos restantes. Logo, a tecnologia que deveria proporcionar ao trabalhador maiores facilidades e ampliação do seu tempo de lazer, acabou escravizando o trabalhador e gerando ainda mais insegurança nos postos de trabalho.

As constantes exigências do mercado sempre são levadas a sério pelas empresas e, freqüentemente, determinam mudanças de procedimentos no trabalho. Os ansiosos tendem mais para o estresse excessivo devido, principalmente, a expectativa negativa que aparece muito antes de quaisquer resultados das mudanças.

De acorde com França e Rodrigues (1999), são as exigências que fazemos de nós mesmos as mais danosas a nossa psique. O mais sadio é que estejamos sempre inconformados e sempre adaptados. Isso significa que, através do inconformismo estamos sempre buscando fazer com que o amanhã seja melhor que o hoje. Entretanto, é indispensável que a pessoa se mantenha adaptada às circunstâncias atuais, mesmo que sejam circunstâncias adversas. 
Sadio seria reclamar das mudanças organizacionais, quando estas estão reduzindo a qualidade de vida no trabalho, para podermos buscar opções que melhorem nossa vida em relação a essas mudanças (reivindicar treinamento, programas de promoção de saúde, mudanças de cargos e salários, etc), outra coisa é estarmos padecendo de hipertensão, úlcera, ansiedade ou enxaqueca por causa dessas mudanças que muitas vezes até melhoram o ambiente de trabalho.

O próprio inconformismo humano exige uma reciclagem constante, ou seja, exige mudanças continuadas e necessidades de adaptação a essas mudanças. Encarar a mudança sob uma perspectiva de crescimento e adequação pode ajudar nossa adaptação, considerá-la uma tarefa tediosa, inútil e humilhante "para quem já sabe tanto", favorece o descontentamento, a ansiedade e, conseqüentemente, o estresse (FRANÇA e RODRIGUES, 1999; GOLLEMAN, 1998; MASLACH, 1998).

Para França e Rodrigues (1999, p.110),

vários autores preferem usar o termo adaptação ativa para designar os processos de enfrentamento que incluem (...) uma posição ativa e critica em que a pessoa tem consciência de que não é uma mercadoria, que não pertence ao empregador nem ao estado, que assume sua posição de produtor para si e para a sociedade. Que tem um projeto de futuro (...).

\section{Considerações finais}

A gestão do estresse no ambiente educacional deve ter como principal objetivo à melhoria da qualidade de vida e isso deve estar assegurado na política de qualidade e recursos humanos da instituição, e identificado na visão e missão do grupo gestor.

Um programa de gestão do estresse no ambiente laboral educacional deve ser sempre encarado com muita responsabilidade e comprometimento de todos os níveis da instituição. Resumindo a idéias de alguns autores citados neste artigo, um programa deste tipo deveria contemplar alguns critérios, a saber: Avaliação dos níveis de estresse no ambiente de trabalho; Desafios e variedade de rotinas a fim de evitar a monotonia dos trabalhos repetitivos; Evitar o excesso de horas extras, evitando-se o desgaste orgânico; Melhorar as condições físicas do trabalho com a adoção de ferramentas adequadas às pessoas e as tarefas ale de um ambiente físico adequado conseguido com o apoio da ergonomia; Investir no aperfeiçoamento pessoal e 
profissional dos funcionários, oportunizando a realização de cursos profissionais e vivencias socioeducativas; Oferecer gratificações simbólicas e personalizadas aos funcionários, como, por exemplo: publicar fotos de reconhecimento dos funcionários nos murais ou revista da escola; Oferecer oportunidades para que os funcionários possam apresentar idéias que melhorem a qualidade e produtividade da empresa, sempre dando feedback para essas idéias; Implementar um código de ética e conduta construído democraticamente e revisado periodicamente.

França e Rodrigues (1999, p.124), oferecem uma lista de intervenções que podem ser implementadas com o objetivo de gerenciar os níveis de estresse pessoal e organizacional, são elas:

Técnicas de relaxamento; Alimentação balanceada; Exercício físico regular; Repouso; Llazer e diversão; Sono apropriado ás necessidades individuais; Psicoterapia e vivências que favoreçam o autoconhecimento; Aprendizado de estratégias de enfrentamento; Administração do tempo livre para atividades ativas e prazerosas; Administração de conflitos entre pares e grupos; Revisão e reestruturação das formas de organização do trabalho; Educação para saúde e, Equacionalização dos planejamentos econômico, social e de saúde.

A equipe gestora educacional, tem sob sua responsabilidade um grande desafio: a gestão do estresse dos seus colaboradores. Esta tarefa exige uma visão multifatorial da realidade envolvendo aspectos econômicos, afetivos, culturais, físicos e ambientais e as ações devem contemplar o maior número possível desses aspectos. A implantação de programas de promoção de saúde, segurança e qualidade de vida, são o ponto de partida para minimizar este tipo de dificuldade.

A gestão do estresse em ambientes educacionais é uma ação de responsabilidade social digna de instituições comprometidas com o desenvolvimento equilibrado de nossa sociedade.

\section{Referências}

DEITOS, F.(a) O mito de Ulisses. Santa Maria: Kaza do Zé, 1997.

(b) Diálogo corporal. Santa Maria: ed. kaza do Zé, 1997. 
FRANÇA, A.C.L. e RODRIGUES, A.L. Stress e Trabalho: Guia básico com abordagem psicossomática. São Paulo: Atlas, 1997.

GOLEMAN, D. Inteligência Emocional. Rio de Janeiro: Objetiva, 1995.

Verdades simples, mentiras essenciais: a psicologia da auto-ilusão. Rio de Janeiro: Objetiva, 1997.

(1998). Trabalhando com a inteligência emocional. Rio de Janeiro: Objetiva.

MASLACH, C. The Truth about Bournout. New York: New Books, 1998.

NAHAS, M. Atividade Física, Saúde e Qualidade de Vida: conceito e sugestões para um estilo de vida ativo. Londrina: Midiograf, 2003.

\section{Sobre os autores:}

(1) Maria Alinele Lucena Soares é Pedagoga pela Universidade Regional do Cariri - URCA e Licenciada em Língua Portuguesa pela Universidade Vale do Acaraú - UVA. Mestranda em Ciências da Educação pela Universidad San Carlos - Paraguai.

E-mail: alinelelucena@ hotmail.com

(2) Ediones Bezerra dos Santos é graduada em Língua Portuguesa e Inglesa pela Universidade Vale do Acarau - UVA. Pós-Graduada em Língua Portuguesa e Arte-Educação pela Universidade Regional do Cariri - URCA. Pós-graduada em Gestão Escolar pela Universidade Federal da Bahia e em Metodologia do Ensino Superior pela Faculdade Kurius - FAK. Mestranda em Ciências da Educação pela Universidad San Carlos - Paraguai.

E-mail: ediones04@hotmail.com

(3) Tereza Ivone Lobo Pinheiro Gurgel é graduada em Letras pela Universidade Estadual do Ceará UECE e Pedagoga pela Universidade Vale do Acarau - UVA. Mestranda em Ciências da Educação pela Universidad San Carlos - Paraguai.

E-mail: Terezaivone@ hotmail.com

(4) Júlia Rosa Santos Sousa é Acadêmica de Letras da Universidade Regional do Cariri - URCA.

E-mail: Julia.rosa.ss@hotmail.com

(5) Hidemburgo Gonçalves Rocha é Professor da Universidade Federal do Ceará e da Universidade Regional do Cariri. Atualmente cursa Doutorado na Universidade Federal do Ceará - UFC.

E-mail: hidemburgo.rocha@bol.com.br

Como citar este artigo (Formato ISO):

SOARES, M. A. L.; SANTOS, E.B.; GURGEL, T.I.L.P.; SOUZA, J.R.; ROCHA, H.G.Gestão das mudanças em organizações educacionais. Id on Line Revista de Psicologia, Novembro de 2010, vol.1, no.12, p.42-49. ISSN 1981-1189. 